\title{
Chapter 10 \\ New Developments in Geographical Information Technology for Urban and Spatial Planning
}

\author{
José António Tenedório \\ Research Centre for Geography and Regional \\ Planning, Universidade NOVA de Lisboa, \\ Portugal \\ Carla Rebelo \\ Research Centre for Geography and Regional \\ Planning, Universidade NOVA de Lisboa, \\ Portugal

\section{Rossana Estanqueiro} \\ Research Centre for Geography and Regional \\ Planning, Universidade NOVA de Lisboa, \\ Portugal
}

\author{
Cristina Delgado Henriques \\ Universidade de Lisboa, Portugal \& Research \\ Centre for Geography and Regional Planning, \\ Universidade NOVA de Lisboa, Portugal

\section{Luís Marques} \\ Research Centre of Land Policy and Valuations, \\ Polytechnic University of Catalonia - \\ BarcelonaTech, Spain \& Research Centre \\ for Geography and Regional Planning, \\ Universidade NOVA de Lisboa, Portugal \\ José Alberto Gonçalves \\ Interdisciplinary Centre for Marine and Environmental \\ Research, Universidade do Porto, Portugal
}

\begin{abstract}
Measuring urban form, modelling 3D point clouds and visualizing data within an (augmented) mixed reality environment through mobile devices are three of the new developments in Geographical Information Technology for urban and spatial planning. New geographical information technology supports data representation for urban and spatial planning. This chapter has two main objectives: (i) to demonstrate that geographical information technology supports every stage of urban and spatial planning, and (ii) to argue that technologies are a means for the external representation of cities and territories. The chapter sections include measuring urban form (quantitative analysis of urban shape), modelling $3 D$ point clouds for the extraction of urban parameters, and the visualization of virtual models through mobile devices.
\end{abstract}

